\title{
Return Migration, Human Capital Accumulation and the Brain Drain*
}

\author{
Christian Dustmann, Itzhak Fadlon and Yoram Weiss
}

April 2010

\begin{abstract}
In this paper we present a model that explains migrations as decisions that respond to where human capital can be acquired more efficiently, and where the return to human capital is highest. The basic framework is a dynamic Roy model in which a worker possesses two distinct skills that can be augmented by learning by doing. There are different implicit prices, in different countries and different rates of skill accumulation. Our analysis contributes to the literature on the selection of immigrants and return migrants by offering a richer framework that may help to accommodate selection of emigrants and return migrants that are not immediately compatible with the one-dimensional skill model. Our analysis also has implications for the debate on brain drain and brain gain. In the two skills model presented here, return migration can lead to a mitigation of the brain drain, or even the creation of a "brain gain", where those who return bring the home country augmented local skills.
\end{abstract}

Key Words: Return migration, human capital accumulation, comparative advantage, brain drain

JEL Classification: J3, J6, F2.

\section{Introduction}

Mobility of workers across national borders responds not only to the return to skills, but also to the opportunity and efficiency of skill acquisition. Efficiency considerations suggest that skills should be acquired where the cost is low and applied where the reward is high. This last aspect has been largely overlooked in the literature that analyzes the causes and forms of migration. Thus, individuals may choose to acquire skills abroad that are highly rewarded in their

*This research has been financially supported by the Austrian, German, Korean, and Norwegian governments through the Multi-donor Trust Fund on Labor Markets, Job Creation, and Economic Growth administered by the World Bank's Social Protection and Labor unit. We thank participants in the applications workshop at the University of Chicago, John Kennan, Jean Marc Robin, Avi Weiss and an anonymous referee for their comments on previous drafts. 
home country and produced cheaply elsewhere. Student migrations are an example with some countries having established themselves as learning centers that provide educational services above those demanded domestically. ${ }^{1}$

There is evidence that, for migrants who returned to their home country, work experience acquired abroad enhances earnings by more than work experience acquired in the home country. Reinhold and Thom (2009) analyze earnings of Mexican emigrants who returned from the U.S. They find that, for these immigrants, the labor market experience accumulated in the US increases earnings by twice the amount than experience accumulated in Mexico. Papers by Barret and O'Connel (2000), Barret and Goggin (2010) and Lara (2006) report similar findings for Ireland and for migrants who returned to Eastern Europe from Western European countries. Co, Gang and Yun (2000) report a wage premium for having been abroad for female return migrants to Hungary. ${ }^{2}$

In this paper, we present a model that explains migrations as decisions that respond to where human capital can be acquired more efficiently and where the return to human capital is highest. The basic framework is one in which a worker possesses two distinct skills that can be augmented by learning by doing while acquiring work experience. The two skills command a different implicit price in different countries. The rate of human capital accumulation is also different in different countries. Thus, a person may move to a country where her skills grow fast and then apply these skills in a different country where these skills have a high price. In this regard, there is an important difference between human and physical or financial assets. Human capital cannot be separated from its owner and he/she must move in order to exploit differences in returns in different locations.

An early paper that discusses higher return in the home country to skills acquired in the host country as a motive that triggers return migration is Dustmann $(1994,1995)$. Other papers that analyze this motive are Borjas and Bratsberg (1996), Santos and Postel-Vinay (2003), De Coulon and Piracha (2005), and Mayr and Peri (2008). These models assume that individual skills are onedimensional. In the single skill model, individuals move based on the prices of this skill in the two countries. If the price is higher in the receiving coun-

\footnotetext{
${ }^{1}$ Recent papers that discuss movement of students are Rosenzweig (2008) who discusses international mobility and Kennan (2009) who examines mobility across US states. Rosenzweig (2008), provides evidence on learning centers. He reports that of the 2 million tertiary students enrolled in education as foreign students, $80 \%$ were educated in only five countries: The US, the UK, Australia, Japan, and Germany.

${ }^{2}$ Return migration is an important phenomenon. Of the foreign born population that entered the UK in the 1990's, and stayed for at least one year, about $40 \%$ had left the UK after another 5 years (see Dustmann and Weiss, 2007). Bijwaard (2008) reports that of those arriving to the Netherlands, about $40 \%$ have left the country within seven years. Christophe and G. Spielvogel (2008) report similar out-migration rates for other countries. The average out-migration rate after 5 years ranges from $28 \%$ for the Netherlands to $60 \%$ for Ireland. Of those immigrants from Mexico who resided in the US in 1995, 3.7 percent had returned in 2000. Return rates differ across education groups: While only $1.6 \%$ of those with an intermediate level of education had returned, $4.3 \%$ and $5 \%$ of the low and highly educated returned. Similar U-shaped patterns for return apply to migration from the US to Argentina and Brazil and from Spain to Chile, Brazil, Argentina and Mexico.
} 
try some highly skilled workers will move. If the possibility to learn abroad is added, some of those who moved will return but those will be the least skilled among the emigrants. Conversely, if the price of the single skill is lower abroad, low skilled workers will emigrate and among these immigrants the most skilled will return. ${ }^{3}$

Considering two skills and allowing comparative advantage to play a role, we obtain "non-hierarchical" migration and remigration patterns with movements that are neither positively nor negatively selected. Among the stayers in the home country, there are some who are more able (in the sense of having a larger endowment of both skills) than some of the movers. At the same time, there may be some movers who are more skilled than some of the stayers. In both comparisons, those who stay have a relatively high component of the skill that is more highly valued in the home country and those who move have a relatively high component of the skill that is more highly valued in the host country. By the same logic, the selection of return migrants may exacerbate or alleviate the impact of migrant selection for the initial out-migration for both emigration- and immigration country. In these regards, the multi-dimensional skill distribution yields a richer set of testable implications than the one skill model of Borjas and Bratsberg (1996).

Our model has important implications for the debate on brain drain and brain gain. In an early paper, Kwok and Leland (1982) describe brain drain as a (permanent) outflow of skilled workers. The model discussed by Borjas and Bratsberg (1996) adds an additional dimension to this: A brain drain issue arises when the price of skills is higher abroad, and may be amplified by those who return being the less able among those who left. In the two skills model presented here, the brain drain is mitigated because those who return come with augmented local skills that are more applicable in the home country. If the proportion of those who return is large enough, aggregate output and even output per capita may increase, implying a brain gain. We also show that by imposing entry standards based on skills that are tailored to the host country the potential brain gain is reduced, because some of those who would return with augmented local skills are barred from skill acquisition abroad. ${ }^{4}$

We discuss these issues in the context of a dynamic Roy model, in which skills vary over time. In contrast to the static Roy model, in which alternatives are characterized by the prices of skills only, our model specifies each alternative in terms of its price and learning opportunities. Such a model can generate planned

\footnotetext{
${ }^{3}$ Borjas and Bratsberg (1996) assume that learning abroad raises local earning by a fixed proportion, irrespective of the duration of the stay abroad. Stark et al. (1998) present a model with employers' learning, which may lead to return migration of those immigrants who were found to be less productive. In Borjas and Bratsberg's framework, this is captured by shocks to earnings after emigration.

${ }^{4}$ Several studies suggest that entry restrictions based on skill in the receiving countries provide an incentive to invest in human capital in the source county (see Mountford, 1997, Docquier and Rapoport, 1997, Stark et al., 1998, and Vidal, 1998). This may then mitigate the brain drain, or even turn it into a brain gain (Beine, Docquier and Rapoport, 2001, Mayr and Peri, 2008).
} 
mobility even under conditions of certainty. ${ }^{5}$ This richer framework is suited to explain migration and remigration between countries with different technologies and a different industrial structure. In particular, it can explain immigration patterns between developed and developing countries that are incompatible with the one skill model that is often applied empirically. ${ }^{6}$

We conduct the analysis in three steps, working backwards. We first examine the return decision of immigrants who are already in the receiving country and investigate who shall return to the home country and when. Based on the results of this last stage, we examine the timing of emigration from the home country. Based on these two considerations, we finally discuss who shall emigrate. We show that these decisions depend crucially on the extent of transferability of work experience acquired abroad to the home country. Specifically, if one can augment the skills that are highly valued in the home country more efficiently abroad, it motivates both emigration and return migration. We then discuss the potential brain gain associated with return migration.

\section{Earning, Learning and Prices}

\subsection{Skills and human capital}

Human capital is viewed here as an aggregate that summarizes individual skills in terms of productive capacity. ${ }^{7}$ The aggregation of individual skills into productive capacity is assumed to take the form

$$
\ln K_{j}(t)=\sum_{s} \theta_{s j} S_{s}(t),
$$

where $K_{j}(t)$ is the productive capacity of a person if he works in country $j$ at time $t, S_{s}(t)$ is the quantity of skill $s$ possessed by the individual at time $t$ and $\theta_{s j}$ is a non-negative parameter that represents the contribution of skill $s$ to production in country $j$. We thus consider skills that are complements in generating the human capital and allow the different skills to have different productivity in different countries. We refer to $\theta_{s j}$ as "prices" because, as we shall show shortly, equilibrium wages are proportional to these productivity factors.

\footnotetext{
${ }^{5}$ Learning as a joint production was first introduced by Rosen (1972a, 1972b). Willis and Rosen (1979), Borjas (1987) and Heckman and Honore (1990) discuss the two skill Roy model. Jovanovic and Nyarko (1997) consider learning in stepping stone occupations. Borjas (1987) and Gould and Moav (2008) use a two skill Roy model to explain emigration patterns but they do not address learning and return migration.

${ }^{6}$ Earlier work (e.g., Cobb-Clark 1993) finds limited evidence for a negative relationship between the source country's income inequality and emigrant wages, as predicted by the oneskill model. Later studies (Feliciano, 2005, Orrenius and Zavodny, 2005, Belot and Hatton, 2008, Chicquiar and Hanson, 2005) find no such relationship. The empirical findings seem compatible with the one skill model only upon introducing additional assumptions, such as a decline in migration costs with education.

${ }^{7}$ A human capital model with multiple skills was first considered by Welch (1969). Heckman et al. (2006) use a two skill model to explain schooling and wages and provide evidence for the importance of both cognitive and non cognitive skills for such outcomes.
} 
To simplify the exposition, we consider the case of only two countries, the receiving country and the country of origin, denoted by $a$ and $b$, respectively, and two skills, denoted by 1 and 2. Each person is characterized by a bundle of two latent skills and in each country there is some bivariate distribution of these skills in the population. ${ }^{8}$ For any fixed price of skills, one can use a linear transformation to translate the latent skills $S_{1}$ and $S_{2}$ that a worker possesses to the potential productive capacities of the worker in each of the two countries, $\ln K_{a}$ and $\ln K_{b}$. We can thus describe a worker by the pair $\left(K_{a}(t), K_{b}(t)\right)$ instead of a pair of latent skills $\left(S_{1}(t), S_{2}(t)\right) .{ }^{9}$

Skills are initially endowed and can then be augmented by acquiring work experience. We consider here a "learning by doing" technology, whereby work in country $j$ augments skill $s$ at a constant rate $\gamma_{s j}$ per unit of time worked. Note the joint production feature of this technology; working in any one country $j$ augments two skills that are potentially useful in both countries. However, experience accumulated in country $j$ may be more relevant to some particular skill and the same skills may be valued differently in the two countries. In this way, we obtain that work experience is transferable but not necessarily general.

We assume that skill 1 is more productive in the receiving country (country a) than in the home country (country $b$ ) while skill 2 is more productive in country $b$ than in country $a$. That is,

$$
\theta_{1 a}>\theta_{1 b}, \theta_{2 b}>\theta_{2 a} \text {. }
$$

We also assume that skill 1 is accumulated at a faster rate than skill 2 in the receiving country, $a$, while skill 2 is accumulated more quickly than skill 1 in the country of origin, $b$. That is,

$$
\gamma_{1 a}>\gamma_{2 a}, \gamma_{2 b}>\gamma_{1 b}
$$

Together, these two assumptions distinguish the two countries in terms of the skills that are used and generated there. Think of country $a$ to be more modern (developed) than country $b$ and suppose that skill 1 represents "managerial" or "intellectual" skills and skill 2 represents "work" or "physical" skills. Then one may expect that managerial skills have a higher relative price in the developed country and also that work experience in the developed country will augment this skill at a higher rate. In contrast, physical skills may be relatively more valuable in country $b$ and also augmented there at a faster rate.

We assume that $\gamma_{s j}$ and $\theta_{s j}$ are all constant parameters and that time flows continuously. Then, a person who works in country $a$ accumulates local human capital at a rate

$$
\frac{\dot{K}_{a}}{K_{a}}=\theta_{1 a} \gamma_{1 a}+\theta_{2 a} \gamma_{2 a} \equiv g_{a a},
$$

\footnotetext{
${ }^{8}$ Individual skills cannot be unbundled from the worker and sold to different employers. For simplicity, we abstract here from the occupational assignment within countries and essentially assume one occupation in each country.

${ }^{9}$ The maintained assumption here is that skills can be measured in some standard units that are common to all countries. The coefficients $\theta_{s j}$ can then be recovered, in principle, from data on earnings (preferably of the same individuals), the duration of stay in the two countries and the choices made by different potential immigrants.
} 
and foreign human capital at a rate

$$
\frac{\dot{K}_{b}}{K_{b}}=\theta_{1 b} \gamma_{1 a}+\theta_{2 b} \gamma_{2 a} \equiv g_{b a}
$$

Similarly, a person who works in country $b$ accumulates local human capital at a rate

$$
\frac{\dot{K}_{b}}{K_{b}}=\theta_{1 b} \gamma_{1 b}+\theta_{2 b} \gamma_{2 b} \equiv g_{b b}
$$

and foreign human capital at a rate

$$
\frac{\dot{K}_{a}}{K_{a}}=\theta_{1 a} \gamma_{1 b}+\theta_{2 a} \gamma_{2 b} \equiv g_{a b}
$$

As seen, the growth in local and foreign human capital for workers in each of the two countries depends on both the prices and learning rates of the two skills. Because prices of skills and the learning rates of each skill differ between the two countries, the rates of change in human capital that are applicable locally or abroad can differ.

\subsection{Assumptions}

For simplicity we assume certainty, infinitely long lived agents and a fixed interest rate $r$. We further assume that learning can take place only for a finite period of time $T$. When an agent reaches that critical age her human capital remains constant for the rest of her life, which captures the idea that learning capacity declines with age. ${ }^{10}$ This assumption implies substitution between learning at home and abroad. The more time a person learns in the home country, the less time is left for learning abroad. Finally, we ignore costs of mobility and non-wage rewards that of course can be important in practice. We do so to focus on the learning issues which have not been investigated much in the literature. ${ }^{11}$

Another simplifying assumption of our model, that is embedded in the linear equations (4) to (7), is that the rates of growth of human capital of each type are constant and thus independent of the initial endowments $K_{a}(0)$ and $K_{b}(0)$. The independence assumption is in line with standard models of human capital such as Rosen (1976) and Ben-Porath (1967). A basic feature of such models is that human capital is self productive. Hence, a skilled person can learn more than an unskilled person. In these models, the growth rate is also influenced by individual decisions such as job switches or investment on the job. ${ }^{12}$ Concavity

\footnotetext{
${ }^{10}$ Empirically, most of the wage growth that can be attributed to work experience takes place over the first ten years of the work career (see Rubinstein and Weiss, 2007).

${ }^{11}$ Selective out-migration and return migration can be influenced by the costs of mobility, especially if these costs differ by level of schooling (see Chiquiar and Hanson, 2005). Grogger and Hanson (2008) estimate the costs of moving across different countries and report fairly large costs.

${ }^{12}$ For instance, Rosen (1976) specifies $\frac{\dot{K}}{K}=h(s)$, where $s$ is "time" or "effort" spent learning on the job. Earnings are then $w=R K(1-s)$, where $r$ is the rental rate of human capital.
} 
of the earnings profile is obtained by a reduction in investment over the life cycle as the remaining time to use the investment shortens. However, the optimal choice of the investment profile is independent of history and $K(0)$ in particular. ${ }^{13}$ In the model presented here, learning by doing occurs at a constant rate as long as a person stays in a given country. However, behavior can influence the growth of human capital by optimal switches across countries, which is very similar to the switches across jobs discussed by Rosen (1972).

In this paper, we shall mainly focus on the degree to which experience acquired in the receiving country, $a$, influences the earning capacity that an immigrant would have if she returns to the country of origin, $b$. We allow country $a$ to be a learning center in the sense that experience acquired there can augment earning capacity locally and in other countries in a substantive way. In particular, we shall consider the case

$$
g_{b a}>g_{a a}>g_{b b}
$$

which means that experience acquired in the host country, $a$, can augment the human capital that is applicable to the home country, $b$, by more than it augments the human capital that is applicable to the host country and also by more than one can obtain by staying in the home country. In contrast, country $b$ is not a learning center. We thus assume throughout that

$$
g_{a b}<g_{b b}<g_{a a}
$$

and

$$
g_{a b}<r<g_{b a} .
$$

Assumption (9) states that experience acquired in country $b$ has only a moderate effect on earning capacity, locally and abroad. Assumption (10) adds that under these circumstances it is unprofitable to delay a move from country $b$ to country $a$, because the growth rate in the human capital applicable to country $a$, while staying in $b$, is below the interest rate. On the other hand, it may be profitable to delay the move back from country $a$ to country $b$, because the growth rate in human capital that is applicable to country $b$, while staying in $a$, exceeds the interest rate. Together, assumptions (8), (9) and (10) allow us to consider emigration and return migration flows that are one directional from the developing country $b$ to the developed country $a$ and back, but not the other way around. Of course, the model is general enough to accommodate flows in both directions and delayed migration, but we shall suppress these possibilities here.

\footnotetext{
${ }^{13}$ The only difference is that for the Ben-Porath model $\dot{k}+\delta k$ is independent of $k(0)$, while in the Rosen model, $\frac{\dot{k}}{k}$ is independent of $k(0)$ (see Weiss, 1986). The reason for using these specific versions is their tractability. Independence of history allows explicit solutions for the optimal investment and earning profiles that are not available otherwise. An important illustration is Lucas (1988) who incorporates human capital into a growth model, using Rosen's specification.
} 


\subsection{Transferability}

Regarding the effect of learning in country $a$ on the earning capacity in country $b$, we distinguish three basic cases.

1) Partial transferability of experience, $g_{b a}<g_{b b}$, which means that by staying in the home country, $b$, one can augment the human capital that is applicable to the home country by more than if work experience is acquired abroad in country $a$. Furthermore, having assumed that $g_{b b}<g_{a a}$, we also have that $g_{b a}<g_{a a}$. That is, experience acquired in the host country augments the human capital applicable to the host country, $K_{a}$, by more than it augments the human capital that is applicable to the home country, $K_{b}$.

2) Strong transferability, $g_{b a}>g_{a a}$, which means that experience acquired in the host country augments the human capital applicable to that country, $K_{a}$, by less than it augments the human capital that is applicable to the home country, $K_{b}$. Furthermore, having assumed that $g_{b b}<g_{a a}$, we also have that $g_{b a}>g_{b b}$. That is, experience acquired in the host country augments the human capital applicable to the home country, $K_{b}$, by more than one would obtain by acquiring work experience in the home country.

3) Super transferability, $g_{b a}>g_{a a}$ (and thus $g_{b a}>g_{b b}$ ) and also $g_{b a}-$ $g_{b b}>r$. In this special case of strong transferability, the learning effects are sufficiently strong to guarantee that, irrespective of the individual's initial skills, learning abroad dominates learning in the home country.

These definitions do not apply directly to transferability of skills or productive capacity but rather to the role of work experience in each country in augmenting skills that have different values in different countries. The worker can always keep the skills that are embodied in her but because these skills are valued differently across countries, each person has two different earnings capacities, one for each country. The question then is how work experience in a given country influences these two earnings capacities. It can be shown that all the cases described above can be satisfied by appropriate choices of the basic parameters of the model, that is, the four growth rates and the four prices of skills in the two countries. ${ }^{14}$ This richness of possibilities arises because the rates of augmentation of the earnings capacity in each of the two countries are different combinations of the skill acquisition rates and prices.

\subsection{Rental rate of human capital and its adaptation}

Firms in each country reward individual skills indirectly by renting human capital at the market-determined rental rate, $R_{j}$, implying that a worker with a given bundle of skills earns in country $j$ at time $t$

$$
w_{j}(t)=R_{j} \exp \left(\sum_{s} \theta_{s j} S_{s}(t)\right) .
$$

\footnotetext{
${ }^{14}$ For instance, for $4 \%<r<12 \%$, the parameters below satisfy super transferability. country $\begin{array}{lllllll}\theta_{1} & \theta_{2} & \gamma_{1} & \gamma_{2} & g_{a} & g_{b}\end{array}$

$\begin{array}{lllllll}\text { a } & 2 & 1 & 5 & 4 & 14 & 21\end{array}$

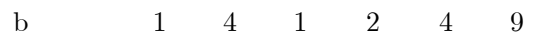


Thus, the parameter $\theta_{s j}$ is proportional to the increase in earning capacity associated with a unit increase in skill $s$ if the individual works in country $j$. Having assumed that $\theta_{s j}$ is independent of the quantity of skill $s$ possessed by the individual, these coefficients may be viewed as the implicit "price" (or "rate of return") of skill $s$ in country $j$. We assume that the rental rate for human capital in the receiving country, $R_{a}$, exceeds the rental rate that human capital receives in country $b, R_{b}$. This difference in rental rates can be sustained if country $a$ has a superior technology and immigration into the receiving country is regulated and only some of those who wish to enter are allowed in.

For several reasons, it is likely that immigrants who enter the receiving country do not immediately receive the same rental rate for their human capital as natives. Firstly, it takes time for immigrants to find a suitable job that matches their skills in the receiving country. Secondly, employers may be uncertain or prejudiced about the immigrants' quality and may update their beliefs based on observed performance. Finally, immigrants may need time to learn the local language and labor market institutions. To describe these processes, we adopt the following functional form

$$
\tilde{R}_{a}(t-\tau)=e^{-\lambda(t-\tau)} R_{b}+\left(1-e^{-\lambda(t-\tau)}\right) R_{a},
$$

where $\tilde{R}_{a}$ is the rental rate for human capital that immigrants receive in country $a$, and $\tau$ is the time of entry into the new country. ${ }^{15}$ That is, the rental rate that an immigrant from country $b$ receives in country $a$ is a weighted average of the rental rate in the country of origin, $R_{b}$, and the rental rate in the receiving country, $R_{a}$. Initially, immigrants receive the same rental rate as abroad, $R_{b}$, but as they spend more time in the host country, the rental rate rises and approaches the rental rate of natives, $R_{a}$. The parameter $\lambda>0$ controls the speed of adjustment. With this specification, the gap in the rental rates of natives and immigrants narrows at a decreasing rate with the duration of stay in the host country.

By the same logic, the rental rate that potential immigrants from country $a$ to country $b$ would receive in country $b$ would be lower than that of natives, $R_{b}$. Our model which allows for the case $g_{b a}>g_{a a}$ and provides incentives for return migration of natives from the home country may also create incentives for some natives of the host country to emigrate from country $a$ to country $b$. To simplify, we assume away such emigration by setting the rental rate in country $b$ for immigrants from country $a$ to zero.

\footnotetext{
${ }^{15}$ Eckstein and Weiss (2004) have estimated the parameters of equation (12) and found that immigrants from the former USSR to Israel, although being highly skilled, have initial wages that are far below those of natives with comparable skills. Dustmann, Frattini and Hall (2009) show that new immigrants to the UK from Eastern Europe, despite having much higher levels of education than natives, start off with wages far lower than those of natives with comparable levels of education. However, as they stay longer in the host country, their wages grow much faster than those of natives.
} 


\section{The Return Decision}

\subsection{The costs and benefits of delayed return}

Imagine an immigrant who moved from country $b$ to $a$ at time $\tau$ and considers whether to return to the home country at time $\varepsilon$, where $\tau<\varepsilon<T$. Conditional on entry at $\tau$, the present value (evaluated at the time of entry $\tau$ ) resulting from staying at country $a$ for a period $\varepsilon-\tau$ and then moving back to country $b$ at time $\varepsilon$ is

$$
\begin{aligned}
V(\varepsilon, \tau)= & K_{a}(\tau) \int_{\tau}^{\varepsilon} e^{\left(g_{a a}-r\right)(t-\tau)} \tilde{R}_{a}(t-\tau) d t+ \\
& R_{b} K_{b}(\tau) e^{g_{b a}(\varepsilon-\tau)}\left[\int_{\varepsilon}^{T} e^{g_{b b}(t-\varepsilon)-r(t-\tau)} d t+e^{g_{b b}(T-\varepsilon)} \frac{e^{-r(T-\tau)}}{r}\right],
\end{aligned}
$$

where $K_{a}(\tau)$ and $K_{b}(\tau)$ are the amounts of human capital applicable to countries $a$ and $b$, respectively, that the worker has upon arrival to the host country at time $\tau$.

Differentiating with respect to $\varepsilon$, we get

$$
\begin{aligned}
V_{\varepsilon}(\varepsilon, \tau)= & K_{a}(\tau) e^{\left(g_{a a}-r\right)(\varepsilon-\tau)} \tilde{R}_{a}(\varepsilon-\tau)-R_{b} K_{b}(\tau) e^{\left(g_{b a}-r\right)(\varepsilon-\tau)} \\
& +\left(g_{b a}-g_{b b}\right) R_{b} K_{b}(\tau) e^{g_{b a}(\varepsilon-\tau)}\left[\int_{\varepsilon}^{T} e^{g_{b b}(t-\varepsilon)-r(t-\tau)} d t+e^{g_{b b}(T-\varepsilon)} \frac{e^{-r(T-\tau)}}{r}\right] .
\end{aligned}
$$

The first term on the RHS of (14) is the marginal gain from postponing the return to the home country in terms of the current earnings in the receiving country. The second term is the marginal cost of delay in terms of the current earnings one may receive upon returning to the home country. The last term is the marginal effect of postponement on life time earnings following the return to the home country which can be positive or negative, depending on the acquisition rates of the human capital that is applicable to the home country, $K_{b}$, in the two countries. If $g_{b a}>g_{b b}$ (that is, local human capital is more efficiently acquired abroad) then a delay raises the amount of $K_{b}$ that a returning immigrant can acquire during the learning period $T$ and can then use in country $b$. Conversely, if $g_{b a}<g_{b b}$, a delayed return is costly in terms of acquiring additional local capital during the remainder of the learning period from $\varepsilon$ to $T$.

We can rewrite (14) as

$$
V_{\varepsilon}(\varepsilon, \tau)=K_{a}(\tau) e^{\left(g_{a a}-r\right)(\varepsilon-\tau)}\left\{\tilde{R}_{a}(\varepsilon-\tau)-R_{b} \frac{K_{b}(\tau)}{K_{a}(\tau)} e^{\left(g_{b a}-g_{a a}\right)(\varepsilon-\tau)} C(\varepsilon)\right\}
$$


where

$$
C(\varepsilon)=1-\left(g_{b a}-g_{b b}\right)\left[\int_{0}^{T-\varepsilon} e^{\left(g_{b b}-r\right) t} d t+\frac{e^{\left(g_{b b}-r\right)(T-\varepsilon)}}{r}\right]
$$

is the marginal cost of delay per unit of human capital that is applicable to the home country, $K_{b}$. The derivative of this cost with respect to $\varepsilon$ is given by

$$
C^{\prime}(\varepsilon)=e^{\left(g_{b b}-r\right)(T-\varepsilon)}\left(g_{b a}-g_{b b}\right) \frac{g_{b b}}{r} .
$$

It is seen that if $g_{b a}>g_{b b}$ then $C(\varepsilon)$ rises in $\varepsilon$, reaching a maximum of $1-\frac{g_{b a}-g_{b b}}{r}$ at $\varepsilon=T$. Conversely, if $g_{b a}<g_{b b}$ then $C(\varepsilon)$ declines in $\varepsilon$, reaching a minimum of $1-\frac{g_{b a}-g_{b b}}{r}$ at $\varepsilon=T$.

Because learning cannot continue beyond time $T$, there is a discontinuity in the marginal cost of delaying the return at $T$. For $\varepsilon>T$, we have

$$
V_{\varepsilon}(\varepsilon, \tau)=K_{a}(T) e^{-r(\varepsilon-\tau)}\left[\tilde{R}_{a}(\varepsilon-\tau)-R_{b} \frac{K_{b}(T)}{K_{a}(T)}\right] .
$$

Hence, by approaching $T$ from above we get in the limit

$$
V_{\varepsilon}(T, \tau)=K_{a}(T) e^{-r(T-\tau)}\left[\tilde{R}_{a}(T-\tau)-R_{b} \frac{K_{b}(T)}{K_{a}(T)}\right] .
$$

However, from (15) and (16) we see that by approaching $T$ from below we get in the limit

$$
V_{\varepsilon}(T, \tau)=K_{a}(T) e^{-r(T-\tau)}\left\{\tilde{R}_{a}(T-\tau)-R_{b} \frac{K_{b}(T)}{K_{a}(T)}\left[1-\frac{g_{b a}-g_{b b}}{r}\right]\right\} .
$$

Thus, if $\frac{g_{b a}-g_{b b}}{r}>0$, the marginal cost of delay jumps up and $V_{\varepsilon}(T, \tau)$ jumps down at $T$ while if $\frac{g_{b a}-g_{b b}}{r}<0$, the marginal cost of delay jumps down and $V_{\varepsilon}(T, \tau)$ jumps up at $T$. Only if $0=\frac{g_{b a}-g_{b b}}{r}$ we have continuity.

We can now summarize the main forces that affect the return decisions. The rising rental rate for human capital in the host country provides an incentive to delay the return. When experience accumulated in the host country raises the human capital applicable to the home country at a faster rate than it raises the human capital applicable to the host country, i.e. $g_{b a}>g_{a a}$, delay becomes more costly because the only way to use the higher earning capacity in the home country is to move there. However, when experience accumulated in the host country raises the human capital applicable to the home country at a faster rate than experience in the home country raises local human capital, i.e. $g_{b a}>g_{b b}$, there is an incentive to delay the return until $T$ because the learning period is finite and, conditioned on returning, learning abroad is more productive. The interest rate also plays a role because, to the extent that investment abroad is productive, one would prefer to receive these benefits sooner rather than later. For this reason, some individuals may prefer to return home prior to $T$, even though $g_{b a}>g_{b b}$. However, when $g_{b a}-g_{b b}>r$, all immigrants will spend the 
whole learning period $T$ in the host country and then some of them will return home.

While the marginal benefit from delay, $\tilde{R}_{a}(\varepsilon-\tau)$, is common to all immigrants, the marginal cost depends on the initial endowments that each immigrant possesses upon entry into the host country. An increase in the ratio $\Omega(\tau) \equiv \frac{K_{b}(\tau)}{K_{a}(\tau)}$ shifts the marginal costs curve upwards, because then the foregone earnings at home while learning abroad are higher at any point in time.

\subsection{Time of return}

We first note that returning after $T$ is never optimal. For $\varepsilon>T$, all learning opportunities have already been exhausted and therefore, the costs of delay are constant, while the marginal benefits from delay continue to rise, as seen in Figures 1 to 3 . Hence, immigrants who have delayed their stay beyond $T$ will always stay longer (see also the on line Appendix). Having stayed in the host country from time $\tau$ up to $T$, an immigrant will return to the home country at $T$ if

$$
K_{a}(T) \int_{T}^{\infty} e^{-r(t-T)} \tilde{R}_{a}(t-\tau) d t \leq R_{b} K_{b}(T) \int_{T}^{\infty} e^{-r(t-T)} d t,
$$

and stay in the host country forever otherwise. Whether an immigrant will actually stay forever, leave at $T$ or leave before $T$ depends on the transferability of experience from the host to the home country. We thus consider three cases.

Partial transferability, $g_{a a}>g_{b b}>g_{b a}$ In this case, the ratio $\frac{K_{b}(t)}{K_{a}(t)}$ declines with the duration of stay in the host country and, therefore, the costs of delayed return decline. That is, moving back to the home country becomes less attractive if the emigrant has already stayed in the host country for a while. This is illustrated in Figure 1. The rising concave curve represents the rental rate that immigrants receive in country $a, \tilde{R}_{a}(\varepsilon-\tau)$, which is the marginal gain from delaying the return to the home country. The downward sloping curve represents the marginal cost in terms of forgone earnings in the home country associated with a delayed return. The intersection of these marginal gain and marginal cost curves determines the duration of stay in the host country that satisfies the first order condition, $V_{\varepsilon}(\varepsilon, \tau)=0$. However, as seen in the Figure 1, the second order condition is not satisfied at this point. Moving a bit to the right the incentive to stay longer increases and moving a bit to the left the incentive to stay is reduced. This is indicated by the arrows in Figure 1. Thus, depending on their initial endowments, workers will either stay in the home country or immigrate to the host country and never return. This result is the same as the occupational specialization results under partial transferability obtained by Weiss (1971).

Strong transferability, $g_{b a}>g_{a a}>g_{b b} \quad$ In this case, the ratio $\Omega(t) \equiv \frac{K_{b}(t)}{K_{a}(t)}$ rises with the duration of stay in the host country. Therefore, the cost of a 
delayed return rises with the duration of stay in the host country. That is, moving back to the home country becomes more attractive if the emigrant has already stayed in the host country for a while. This is illustrated in Figure 2. In this case, if an intersection exists for $\varepsilon$, such that $\tau<\varepsilon<T$, it satisfies the second order conditions. Therefore, an optimal solution may exist such that an immigrant who entered the receiving country will later choose to return to the home country. This happens, because during the stay in the host country, the human capital applicable in the home country, $K_{b}$, rises at a faster rate than the human capital that is applicable to the host country, $K_{a}$. Examining Figure 2, it is seen that immigrants with a higher $\Omega(\tau)$ will leave sooner after arrival (i.e., $\varepsilon-\tau$ declines) because the foregone earnings at home while learning abroad are higher for them. For sufficiently low $\Omega(\tau)$, the cost function will shift down and the intersection will occur in the range in which $\varepsilon>T$, but then an intersection does not satisfy the second order conditions and, based on condition (21), the immigrant either leaves at $T$ or stay forever.

Super transferability, $g_{b a}>g_{a a}>g_{b b}$ and $g_{b a}-g_{b b}>r$ In this case, the marginal costs of delay in terms of forgone earnings in the home country become negative for all $\varepsilon<T$, irrespective of the initial skill endowments. Because of the positive benefits from delayed return associated with the rising rental rate, $\tilde{R}_{a}(\varepsilon-\tau)$, all immigrants will stay until $T$. Then, based on condition (21) the immigrant either leaves at $T$ or stay forever. This case is illustrated in Figure 3.

\section{Who Returns and Who Leaves}

In the on line Appendix, we show that in all the considered cases, immigrants who choose to emigrate will do it at time $\tau=0$. The basic intuition is that if the immigrant plans to stay in the host country, then, by leaving early, she can increase the amount of $K_{a}$ that will be used in the host country. Similarly, if the immigrant plans to return to the home country she can increase, by leaving early, the amount of $K_{b}$ that will be used in the home country. In either case, the limited learning period is used more efficiently by an early exit.

In our model immigrants are forward looking and take their prospective return decisions into account. Individuals with different initial endowments of the two skills, $S_{1}(0)$ and $S_{2}(0)$, make different emigration decisions that depend on the prices and the learning rates of the two skills in the host and the home country. Generally, individuals with a relatively higher endowment of the skill that is more highly rewarded in the home country (skill 2) are more likely to stay in the home country and those individuals with a relatively higher endowment of the skill that has a higher value in the host country (skill 1) are more likely to emigrate. However, the precise determination of these groups depends on whether emigrants plan to return or not and when. We shall therefore discuss the three basic cases outlined above separately. 


\subsection{Partial Transferability, $g_{a a}>g_{b b}>g_{b a}$}

We have shown that, in this case, an immigrant will either stay forever or leave immediately at time 0 . The choice between these two alternatives is reduced to a comparison of the potential life time earnings in the two countries and a person will wish to emigrate to the receiving country immediately if

$R_{b} K_{b}(0)\left[\int_{0}^{T} e^{\left(g_{b b}-r\right) t} d t+\frac{e^{\left(g_{b b}-r\right) T}}{r}\right]<K_{a}(0)\left[\int_{0}^{T} e^{\left(g_{a a}-r\right) t} \tilde{R}_{a}(t) d t+e^{\left(g_{a a}-r\right) T} \int_{0}^{\infty} e^{-r t} \tilde{R}_{a}(t+T) d t\right]$.

Recalling our definition, $\Omega(t) \equiv \frac{K_{b}(t)}{K_{a}(t)}$, this comparison of present values can be rewritten in the form

$$
\Omega(0)<\frac{\int_{0}^{T} e^{\left(g_{a a}-r\right) t} \tilde{R}_{a}(t) d t+e^{\left(g_{a a}-r\right) T} \int_{0}^{\infty} e^{-r t} \tilde{R}_{a}(t+T) d t}{R_{b}\left[\int_{0}^{T} e^{\left(g_{b b}-r\right) t} d t+\frac{e^{\left(g_{b b}-r\right) T}}{r}\right]} \equiv \Omega_{p} .
$$

Thus, there is some critical value of $\Omega(0)$ denoted as $\Omega_{p}$ that triggers emigration. We emphasize that $\Omega_{p}$ (as well as the trigger values defined below) is not an additional independent parameter. Rather, it is an endogenously determined function of the basic parameters that summarizes the impact of planned future immigration decisions on the present value of life time earnings that is associated with alternative current choices. For instance, an increase in $R_{a}$ relative to $R_{b}$ raises $\Omega_{p}$, which induces a larger proportion of the population to emigrate and never return.

We can further reduce this relationship and rewrite (23) as

$$
S_{2}(0)<\frac{\ln \Omega_{p}}{\theta_{2 b}-\theta_{2 a}}+\frac{\theta_{1 a}-\theta_{1 b}}{\theta_{2 b}-\theta_{2 a}} S_{1}(0) .
$$

Because $\tilde{R}_{a}(t)>R_{b}$ and $g_{a a}>g_{b b}$, the expected earnings per unit of initial human capital are higher in country $a$ than in country $b$ and, therefore, $\ln \Omega_{p}>$ 0 . Different individuals have different skills and the set of people that wish to emigrate is all those whose bundle of initial skills (a pair $\left(S_{1}(0), S_{2}(0)\right)$ places them below the bold line described in Figure 4. Because skill 1 has higher value in country $a$, individuals with relatively higher endowment of that skill are more likely to emigrate. The slope of the boundary line is $\frac{\theta_{1 a}-\theta_{1 b}}{\theta_{2 b}-\theta_{2 a}}$ which, under our assumptions, is positive but can be above or below $1 .{ }^{16}$ The graph

\footnotetext{
${ }^{16}$ Partial transferability and condition (9) require

$$
\frac{\gamma_{2 b}}{\gamma_{1 b}}>\frac{\theta_{1 a}-\theta_{1 b}}{\theta_{2 b}-\theta_{2 a}}>\frac{\gamma_{2 a}}{\gamma_{1 a}}
$$

and, by assumption,

$$
\frac{\gamma_{2 b}}{\gamma_{1 b}}>1>\frac{\gamma_{2 a}}{\gamma_{1 a}}
$$
}


is drawn for the case in which the prices of skill 2 differ across countries less than the prices of skill 1, that is, $\frac{\theta_{1 a}-\theta_{1 b}}{\theta_{2 b}-\theta_{2 a}}>1$. This condition can be compared to the one skill model of Borjas and Bratsberg (1996) by examining the special case of perfect correlation between the two skills, $S=S_{1}(0)=S_{2}(0)$. Then the condition $\frac{\theta_{1 a}-\theta_{1 b}}{\theta_{2 b}-\theta_{2 a}}>1$ implies that

$$
\frac{d \ln K_{a}}{d S}=\theta_{1 a}+\theta_{2 a}>\frac{d \ln K_{b}}{d S}=\theta_{1 b}+\theta_{2 b} .
$$

That is, a common increase in both skills raises log earnings in country $a$ by more than it increases log of earnings in country $b$. Hence, in the one skill model individuals with low $S$ would prefer to stay in the home country, while those with high $S$ will emigrate. In the two dimensional case discussed here, the two skills are not perfectly correlated. Therefore, although $\frac{\theta_{1 a}-\theta_{1 b}}{\theta_{2 b}-\theta_{2 a}}>1$, some of those who choose to stay in the home country are more "able" (in the sense of having a higher endowment of both skills) than some of those who choose to emigrate. This is illustrated by points $a$ and $b$ in Figure 4 . At the same time, some of those who choose to stay in the home country are less "able" (in the sense of having a lower endowment of both skills) than some of those who choose to emigrate. This is illustrated by points $c$ and $d$ in Figure 4 . It is only if we restrict attention to comparisons along lines with a slope of 1 that all the individuals who emigrate are more able than all the individuals who stay. In this regard, the two dimensional model provides a richer set of possibilities than the one dimensional model.

\subsection{Strong Transferability, $g_{b a}>g_{a a}>g_{b b}$}

In this case, some individuals may stay in the home country, some may emigrate and return at some $\varepsilon$ between 0 and $T$ and some will emigrate and never return. Individuals for whom $V_{\varepsilon}(0,0)<0$ will stay in the home country; they do not want to leave at time 0 nor do they want to exit later, as we show in the appendix. Individuals for whom $V_{\varepsilon}(0,0)>0$, will emigrate and stay in the host country at least some time. By (15) and (16),

$$
V_{\varepsilon}(0,0)=K_{a}(0)\left\{\tilde{R}_{a}(0)-R_{b} \frac{K_{b}(0)}{K_{a}(0)} C(0)\right\} .
$$

If $C(0)>0$, those for whom

$$
\frac{K_{b}(0)}{K_{a}(0)} \geq \frac{1}{C(0)} \equiv \Omega_{s}
$$

will stay in the home country and those for whom $\frac{K_{b}(0)}{K_{a}(0)}<\frac{1}{C(0)}$ will emigrate. If $C(0)<0$, everyone will emigrate. Among those who emigrate, workers for whom

$$
\frac{K_{b}(0)}{K_{a}(0)}<\frac{r e^{\left(g_{a a}-g_{b a}\right) T}}{R_{b}} \int_{T}^{\infty} e^{-r(t-T)} \tilde{R}_{a}(t) d t \equiv \Omega_{n r},
$$


will stay in the host country and those for whom .

$$
\frac{K_{b}(0)}{K_{a}(0)}>\Omega_{n r},
$$

will return to the home country return some time before $T$.

The case with $C(0)>0$ and $\Omega_{s}>\Omega_{n r}$ is presented in Figure 5. ${ }^{17}$ The population is then divided into three groups. Those with high initial endowment of the skill that is highly valued in country $b, S_{1}(0)$ relative to to their endowment of the skill that is highly valued in country $a, S_{2}(0)$, will stay in the home country. The others will emigrate and, among them, those for whom $S_{1}(0)$ is high relatively to $S_{2}(0)$ will stay in the host country for good. The solid boundary lines are now drawn with a slope that is less than 1 , which is a necessary outcome of strong transferability that requires

$$
1>\frac{\gamma_{2 a}}{\gamma_{1 a}}>\frac{\theta_{1 a}-\theta_{1 b}}{\theta_{2 b}-\theta_{2 a}} .
$$

Would we restrict ourselves to the one dimensional case, as in Borjas and Bratsberg (1996), this requirement would imply that all individuals who stay in the home country are more able than all immigrants that return who are in turn more able than all immigrants who stay abroad. This seems implausible in the case of immigration from developing countries to a developed country. In this regard, a two skill model is much more appealing, because it allows a richer set of possibilities.

\subsection{Super Transferability, $g_{b a}>g_{a a}>g_{b b}$ and $g_{b a}-g_{b b}>r$}

In this case, all immigrants stay in the host country until $T$ and then some return, at $T$, to the home country and others stay permanently. Those who go abroad and return earn

$$
W_{r}(T)=K_{a}(0) \int_{0}^{T} e^{-r t+g_{a a} t} \tilde{R}_{a}(t) d t+e^{\left(g_{b a}-r\right) T} \frac{R_{b} K_{b}(0)}{r} .
$$

${ }^{17}$ This case requires

$$
\frac{1}{C(0)}>\frac{r e^{\left(g_{a a}-g_{b a}\right) T}}{R_{b}} \int_{T}^{\infty} e^{-r(t-T)} \tilde{R}_{a}(t) d
$$

By (16),

$$
C(0)=1-\left(g_{b a}-g_{b b}\right)\left[\int_{0}^{T} e^{\left(g_{b b}-r\right) t} d t+\frac{e^{\left(g_{b b}-r\right) T}}{r}\right] .
$$

Thus, $C(0)>0$ if $g_{b a}-g_{b b}$ is small or if the learning period $T$ is short and $C(0)<0$ otherwise. If $C(0)<0$, the top region in Figure 5 disappears. 
Those who go abroad and do not return earn

$$
W_{s}(T)=K_{a}(0) \int_{0}^{T} e^{-r t+g_{a a} t} \tilde{R}_{a}(t) d t+K_{a}(0) e^{\left(g_{a a}-r\right) T} \int_{T}^{\infty} e^{-r(t-T)} \tilde{R}_{a}(t) d t .
$$

Those who stay home earn

$$
W_{h}(T)=R_{b} K_{b}(0) \int_{0}^{T} e^{-r t+g_{b b} t} d t+e^{\left(g_{b b}-r\right) T} \frac{R_{b} K_{b}(0)}{r} .
$$

We can show that, under our assumption that $g_{b a}-g_{b b}>r$, everyone will want to emigrate, because going abroad and returning always dominates staying at home. That is, even if one earns nothing abroad, the increase in earning capacity after the completion of training abroad more than compensates for the forgone earnings at home during the training period, $T .{ }^{18}$

As it does not make sense that everyone can enter the host country, imagine that the government of the receiving country restricts entry by requiring a minimal level of skill 1 which, by assumption, is more valuable in country $a$. Then, those with lower endowment of skill 1 than the minimal required value, given by $S_{1}^{m}(0)$, must stay in the home country and the rest are divided according to the shaded areas indicated in Figure $6 .{ }^{19}$ For those who are allowed in, there is a critical value such that emigrants with $\frac{K_{b}(0)}{K_{a}(0)}>\Omega_{r}(0)$ will choose to return to the home country at time $T$ (because for them $W_{r}(T)>W_{s}(T)$ ), while those for whom $\frac{K_{b}(0)}{K_{a}(0)}<\Omega_{r}(0)$ will stay in the host country (because for them $\left.W_{r}(T)<W_{s}(T)\right)$. This critical value is given by

$$
\Omega_{r}(0)=r e^{\left(g_{a a}-g_{b a}\right) T}\left[\frac{R_{a}}{r R_{b}}+\frac{R_{b}-R_{a}}{(r+\lambda) R_{b}} e^{-\lambda T}\right] .
$$

Every immigrant with a bundle of skills above the positively sloped solid line in Figure 6 will return to the home country and all others will stay in the host country. ${ }^{20}$ The boundary is drawn again with a slope less than 1 , as implied by strong transferability, which also applies here.

\footnotetext{
${ }^{18}$ To see that, we write

$$
W_{r}(T)-W_{h}(T)>f(T) \equiv \frac{R_{b} K_{b}(0)}{r}\left[e^{\left(g_{b a}-r\right) T}-e^{\left(g_{b b}-r\right) T}-r \int_{0}^{T} e^{-r t+g_{b b} t} d t\right],
$$

and note that $f(0)=0$ and

$$
\begin{aligned}
f^{\prime}(T) & =\frac{R_{b} K_{b}(0)}{r}\left[\left(g_{b a}-r\right) e^{\left(g_{b a}-r\right) T}-g_{b b} e^{\left(g_{b b}-r\right) T}\right] \\
& >\frac{R_{b} K_{b}(0) e^{\left(g_{b b}-r\right) T}}{r}\left[g_{b a}-r-g_{b b}\right]>0 .
\end{aligned}
$$

This implies that, for every $T>0, f(T)>0$ and $W_{r}(T)>W_{h}(T)$.

${ }^{19} \mathrm{Such}$ a restriction is analyzed by Djajic (1989) in a one skill framework.

${ }^{20}$ The intercept is taken here to be negative, which would be the case if $\lambda$ is sufficiently small. For a large $\lambda$, the intercept can be positive.
} 


\section{Closing the model}

We described here the immigration and remigration decisions of workers in a developing country, taking as given the rental rates of human capital in the two countries, $R_{a}$ and $R_{b}$. These two parameters respond to changes in demand and supply of labor and to the immigration policy of the receiving country. A simple way to close the model is to postulate an aggregate production function

$$
Y_{j}=F^{j}\left(N_{j}, H_{j}\right),
$$

where $Y_{j}$ is the aggregate output of a single (composite) good in country $j, N_{j}$ is the aggregate physical (non human) capital employed in country $j$ and $H_{j}$ is the aggregate human capital embodied in the population of country $j$. Assuming a constant return to scale technology and free mobility of capital, the capital labor ratio (in efficiency units) in each country is uniquely determined by the maximum profit condition

$$
F_{N_{j}}^{j}\left(\frac{N_{j}}{H_{j}}\right)=r
$$

where $r$ is the internationally determined return to capital. Having a fixed capital labor ratio in each country, the rental rates for human capital $R_{a}$ and $R_{b}$ are also uniquely determined. A difference between the two countries in the rental rates of human capital resulting from different technologies can be sustained if mobility of workers is restricted. If some workers move from country $b$ to country $a$ then, depending on the initial skills of these workers, there is a certain proportional increase in $H_{a}$ and a certain proportional decrease in $H_{b}$. Following the adjustments in non human capital the aggregate output in each country, $Y_{j}$, will change by the same proportions as the change in aggregate human capital. Finally, we can translate these results into a per capita framework by rewriting the production function (35) as $y_{j}=F^{j}\left(n_{j}, h_{j}\right)$, where $y_{j}$ is per capita income in country $j, n_{j}$ is the per capita physical (non human) capital employed in country $j$, and $h_{j}$ is the per capita human capital embodied in the population of country $j .{ }^{21}$

\section{Brain Gain and Brain Drain}

We first observe that in the absence of externalities, individual rationality implies that the reduction in local output caused by emigration is always lower than the gain that the immigrant obtains abroad. Hence, there is always a potential gain for the developing countries if their citizens can apply their skills where they receive the highest rewards. However, in the absence of transfers, emigration can have negative effects on those who remain behind, workers as

\footnotetext{
${ }^{21}$ This simple analysis is completely static. Santos and Postel-Vinay (2003) provide a dynamic analysis in which migration and return migration generate technological diffusion that affects the rate of growth in the receiving and sending countries. Business cycle effects can also be added by letting the rental rates in the two countries vary with the cycle.
} 
well as capital owners, through changes in factor prices or a reduced tax base and ability to finance local public goods. It was therefore suggested that emigrants, or the receiving developed countries, should compensate the developing countries for these losses (see Bagwhati 1976, Part I). In practice, such taxation is hard to accomplish and we shall be concerned here only with the proportional change in local per capita human capital caused by emigration and return migration, which under our assumptions is the same as the proportional change in local per capita income. We refer to a reduction in the per capita human capital in the home country (country $b$ ) as a brain drain and to an increase in the per capita human capital in the home country as a brain gain.

Consider the following thought experiment. Initially, there is no labor mobility between countries. Then, at a later time, costless labor migration becomes feasible. We wish to examine the implications of such a change for the developing country (country $b$ ). We have seen that with partial transferability emigrants from country $b$ to country $a$ do not return to their home country. Therefore, in this case, local aggregate output must decline. However, output per capita in the home country may increase if the skill composition of emigrants is such that per capita endowment of human capital $h_{b}$ rises. ${ }^{22}$ If experience acquired in the host country is strongly transferable, some immigrants return and some stay, but because immigrants with different initial skills return at different times it is hard to evaluate the aggregate outcome. However, with super transferability, all immigrants that return will do so at the end of the learning period, $T$. Moreover, every immigrant that returns generates a brain gain of

$$
\frac{R_{b} K_{b}(0) e^{\left(g_{b a}-r\right) T}}{r}-R_{b} K_{b}(0)\left[\int_{0}^{T} e^{-r t+g_{b b} t} d t+\frac{e^{\left(g_{b b}-r\right) T}}{r}\right]
$$

which is always positive under super transferability (see footnote 18). On the other hand, there may be a per capita gain or loss from those who leave and do not return. The brain gain (loss) from any emigrant that does not return is determined by comparing his potential life time earnings if he would have stayed in the home country, given by $R_{b} K_{b}(0)\left[\int_{0}^{T} e^{-r t+g_{b b} t} d t+\frac{e^{\left(g_{b b}-r\right) T}}{r}\right]$, to the average life time earnings prior to emigration. Taking all these possibilities into account, output per capita in the home country can increase if the proportion of returning immigrants is large enough, thus leading to a brain gain.

To the extent that the host country imposes an entry skill standard, the probabilities of exit and return must also be conditioned on having the minimal level of $S_{1}(0)$ required for entry. By imposing such a standard, the home country "gains" some of those who have low levels of skill 1 and would not have returned

\footnotetext{
${ }^{22}$ This will happen if the average skills of the stayers is higher than the population mean. Assuming that skills are distributed in the population according to a joint normal distribution, this will occur if the variance of $K_{b}$ (in the home country) exceeds the covariance between $K_{a}$ and $K_{b}$. However, if the inequality is reversed, emigration will reduce the average per capita endowment of human capital. See also Heckman and Honore (1990) and Borjas (1987).
} 
(because they have relatively low amounts of the local skill, 2) but it "loses" those with low levels of skill 1 who would have returned to the home country with their augmented local skills that they would have acquired abroad. The second group may be more valuable to the home country if their weight among unaccepted immigrants is substantial. Hence, it is quite possible that by imposing a skill standard the brain drain problem faced by the home country will be aggravated. Moreover, from the point of view of the receiving country, the selection by local skill restricts entry of immigrants who would return to their home country anyway, which may not be the intended outcome of the policy.

\section{Conclusion}

We have presented a tractable model that focuses on the incentives to return immigration based on investment considerations. ${ }^{23}$ It was shown that, under some conditions, the model can generate a brain gain. The basic idea is that some countries are learning centers where one can learn skills more effectively, including skills that are applicable to the home country. Therefore, some individuals who emigrate will return to apply their acquired skills in the home country. Moreover, those who return have a relatively high endowment of the skill that is more valued in the home country.

We have extended the work of Borjas (1987) by adding learning considerations to the Roy model. This richer framework has the potential to explain migration and remigration patterns between developed and less developed countries that differ in technology and industrial structure. An empirical application of such a model requires measures of the various dimensions of skills. Schooling alone is insufficient for this purpose but one can add the "task content" of occupations as in Autor and Handel (2009).

We discussed here only learning by doing on the job. However, the basic ideas also apply to learning at school. A policy issue that applies to both cases is how to allocate the gains from immigration among individuals and in between countries. Tuition policies in the context of student migration are discussed in Rosenzweig (2006) and Kennan (2009). This problem is somewhat more complicated in the case of learning on the job, where the opportunity costs are not directly observable. Further issues arise if one can move to a learning center in order to acquire skills that are applicable in a third country rather than the home country, resulting in chain migration. In this case, the natural solution would be to require a payment from the immigrant for the "general" human capital that she acquired. Finally, an important issue that we did not discuss is the potential externalities if the skills of different workers in a given economy are complements. Hence, brain drain or gain can have magnified consequences

\footnotetext{
${ }^{23}$ Other reasons for return migration and their implications, such as consumption preferences, retirement, and purchasing power differences are discussed elsewhere (Dustmann, 1995, Dustmann and Kirchkamp, 2002). Business cycle effects are discussed in Mandelman and Zlade (2008).
} 
through the impacts of emigration (immigration) on the workers who stay in

the home country and also further consequences for the workers in the receiving country.

\section{References}

[1] Autor, D. and M. Handel (2009), "Putting Tasks to the Test: Human Capital, Job Tasks and Wages" NBER WP 15116.

[2] Barrett, A. and P. O'Connell, "Is There a Wage Premium for Returning Irish Migrants?," 2001. Economic and Social Review, 32, pp 1-21.

[3] Barrett, A. and J. Goggin, "Returning to the Question of a Wage Premium for Returning Migrants," 2010. IZA Discussion Paper No. 4736.

[4] Beine, M. Docquier and H. Rapoport (2001), "Brain Drain and Economic Growth: Theory and Evidence," Journal of Development Economics, 64, 275-289.

[5] Belot, M. and T. Hatton (2008), "Immigrant Selection in the OECD", DP No. 571, The Australian National University.

[6] Ben-Porath, Y. (1967), " "The Production of Human Capital and the LifeCycle Earnings," The Journal of Political Economy, 1967, 75, 352-365.

[7] Bhagwati, J. (1976), "The International Brain Drain and Taxation: A survey of the issues," in J. Bhagwati (editor) The Brain Drain and Taxation, Amsterdam: North Holland.

[8] Bijwaard, G. (2008) "Modeling Migration Dynamics of Immigrants," Tinbergen Institute Discussion Paper TI 2008-070.

[9] Borjas, G. (1987), "Self-Selection and the Earnings of Immigrants," American Economic Review, 77, 531-553.

[10] Borjas, G. and B. Bratsberg (1996), "Who Leaves? The Outmigration of the Foreign-Born," The Review of Economics and Statistics, 78, 65-76.

[11] Chiswick, B. (1999), "Are Immigrants Favorably Self-Selected?" American Economic Review - Papers and Proceedings, 89, 181-185

[12] Co, C., I. Gang, and M. Su-Yun, "Returns to returning," Journal of Population Economics, 2000, 13, 57-79.

[13] Cobb-Clark, D. (1993), "Immigrant Selectivity and Wages: The Evidence for Women", American Economic Review, 83, 986-993

[14] Christophe, D. and G. Spielvogel (2008), "Return Migration: A New Perspective" in International Migration Outlook: SOPEMI 2008. 
[15] De Coulon, A. and M. Piracha (2005), ŞSelf-selection and the Performance of Return Migrants: The Source-county PerspectiveŤ, Journal of Population Economics Vol. 18 No. 4 pp. 779-807

[16] Djajic, S. (1989), "Skills and the Pattern of Migration: The role of qualitative and Quantitative Restrictions on International Labor Mobility," International Economic Review, 30, 795-809.

[17] Dustmann, C. (1994), "Return Intentions of Migrants: Theory and Evidence," CEPR DP906

[18] Dustmann, C. (1995), "Savings Behavior of Migrant Workers - A Life Cycle Analysis," Zeitschrift fuer Wirtschafts-und Sozialwissenschaften, 4, 511533.

[19] Dustmann, C. (1997), "Return Migration, Uncertainty and Precautionary Savings." Journal of Development Economics, 52, 295-316.

[20] Dustmann, C. and Y. Weiss (2007), "Return Migration: Theory and Empirical Evidence from the UK," British Journal of Industrial Relations, 45, 236-256.

[21] Dustmann, C. and O. Kirchkamp (2002), "The Optimal Migration Duration and Activity Choice after Re-migration", Journal of Development Economics, Vol. 67, pp. 351-372.

[22] Dustmann, C., T. Frattini and Caroline Halls (2010), "Assessing the Fiscal Costs and Benefits of A8 Migration to the UK", Fiscal Studies, Vol. 31, No. 1 , pp. 1 - 41

[23] Eckstein, Z. and Y. Weiss (2004), "On the Wage Growth of Immigrants: Israel, 1990-2000," Journal of the European Economic Association, 2, 665695.

[24] Feliciano, C. (2005), "Educational Selectivity in U.S. Immigration: How do Immigrants Compare to those left behind?" Demography, 42, 131-152.

[25] Gould, E. and O. Moav (2008), "When Is 'Too Much' Inequality Not Enough? The Selection of Israeli Emigrants," Unpublished Manuscript, Hebrew University.

[26] Grogger, J. and G. Hanson (2008), "Income maximization and the Selection and Sorting of International Migrants", NBER WP 13821.

[27] Heckman, J. and B. Honore (1990), "The Empirical Content of the Roy Model," Econometrica, 58, 1121-4.

[28] Heckman, J., J. Stixrud and S. Urzua (2006), "The Effects of Cognitive and Non-cognitive Abilities on Labor Market Outcomes and Social Behavior," Journal of Labour Economics, 24, 411-482. 
[29] Iara, A. (2006), "Skill Diffusion by Temporary Migration? Returns to Western European Working Experience in the EU Accession Countries," A Global Development Network Working Paper.

[30] Jovanovic, B. and Nyarko, Y. (1997), "Stepping Stone Mobility," CarnegieRochester Conference on Public Economics, 46, 289-325

[31] Kennan, J. (2009), "Higher Education Subsidies and Human Capital Mobility", mimeo., University of Wisconsin-Madison

[32] Kwok, V. and H. Leland (1982), "An Economic Model of the Brain Drain," American Economic Review, 72, 91-100.

[33] Lucas, R. (1988), "On the Mechanics of Economic Development," Journal of Monetary Economics, 22, 3-42.

[34] Mandelman, F. and A. Zlate (2008), "Immigration and the Macroeconomy," Federal Reserve Bank of Atlanta, WP 2008-25.

[35] Mayr, K. and G. Peri (2008), "Return Migration as Channel for Brain Gain," CReAM DP. 04/08.

[36] Mountford, A. (1997), "Can a Brain Drain be Good for Growth in the Economy?," Journal of Development Economics, 53, 287-303.

[37] Orrenius, P. and M. Zavodny (2004), "Self-Selection Among Undocumented Immigrants from Mexico", Journal of Development Economics, 78, 215-240

[38] Reinhold, S. and K. Thom (2009), "Temporary Migration, Skill Upgrading, and Legal Status: Evidence from Mexican Migrants", MEA DP 182-2009

[39] Rooth, D. and J. Saarela (2007), "Selection in Migration and Return Migration: Evidence from Micro Data", Economic Letters, 94, 90-95.

[40] Rosen, S. (1972a), Learning and Experience in the Labor Market," Journal of Human Resources, 7, 326-342.

[41] Rosen, S. (1972b), "Learning by Experience as Joint Production," The Quarterly Journal of Economics, 1972, 86, 366-82.

[42] Rosen, S. (1976), "A theory of Life Earnings," The Journal of Political Economy, 1976, 84, s45-s67.

[43] Rosenzweig, M. (2008), "Higher Education and International Migration in Asia: Brain Circulation", mimeo, Yale University.

[44] Roy, A. (1951), "Some Thoughts on the Distribution of Earnings," Oxford Economic Papers, 3, 135-146.

[45] Rubinstein Y. and Y. Weiss (2006), "Post School Wage Growth: Investment, Search and Learning," Handbook of the Economics of Education, edited by E. Hanushek and F. Welch. Amsterdam: Elsevier. 
[46] Santos, M. and F. Postel-Vinay (2003), "Migration as a source of Growth: The Perspective of a Developing Country", Journal of Population Economics 16, 161-175.

[47] Sjaastad, L. (1962), "The Costs and Returns of Human Migration" The Journal of Political Economy, 70, 80-93.

[48] Stark, O., Helmenstein, C. and A. Prskawetz (1997), "A Brain Drain with a brain Gain," Economic Letters, 55, 227-234.

[49] Stark, O., Helmenstein C. and A. Prskawetz (1998), "Human Capital Depletion, Human Capital Formation, and Migration: A Blessing of a Curse?" Economic Letters, 60, 363-367.

[50] Vidal, J. (1998), "The Effect of Emigration on human Capital Formation," Journal of Population Economics, 11, 589-600.

[51] Weiss, Y. (1971), "Learning by Doing and Occupational Specialization," Journal of Economic Theory, 3, 189-199.

[52] Weiss, Y. (1986), "The Determination of Life Cycle Earnings: A Survey." Handbook of the Labor Economics, edited by O. Ashenfelter an R. Layard, Amsterdam: Elsevier.

[53] Welch, F. (1969), "Linear Synthesis of Skill Distribution," Journal of Human Resources, 4, 311-327.

[54] Willis, R. and S. Rosen (1979), "Education and Self-Selection," The Journal of Political Economy, 87, S7-S36. 


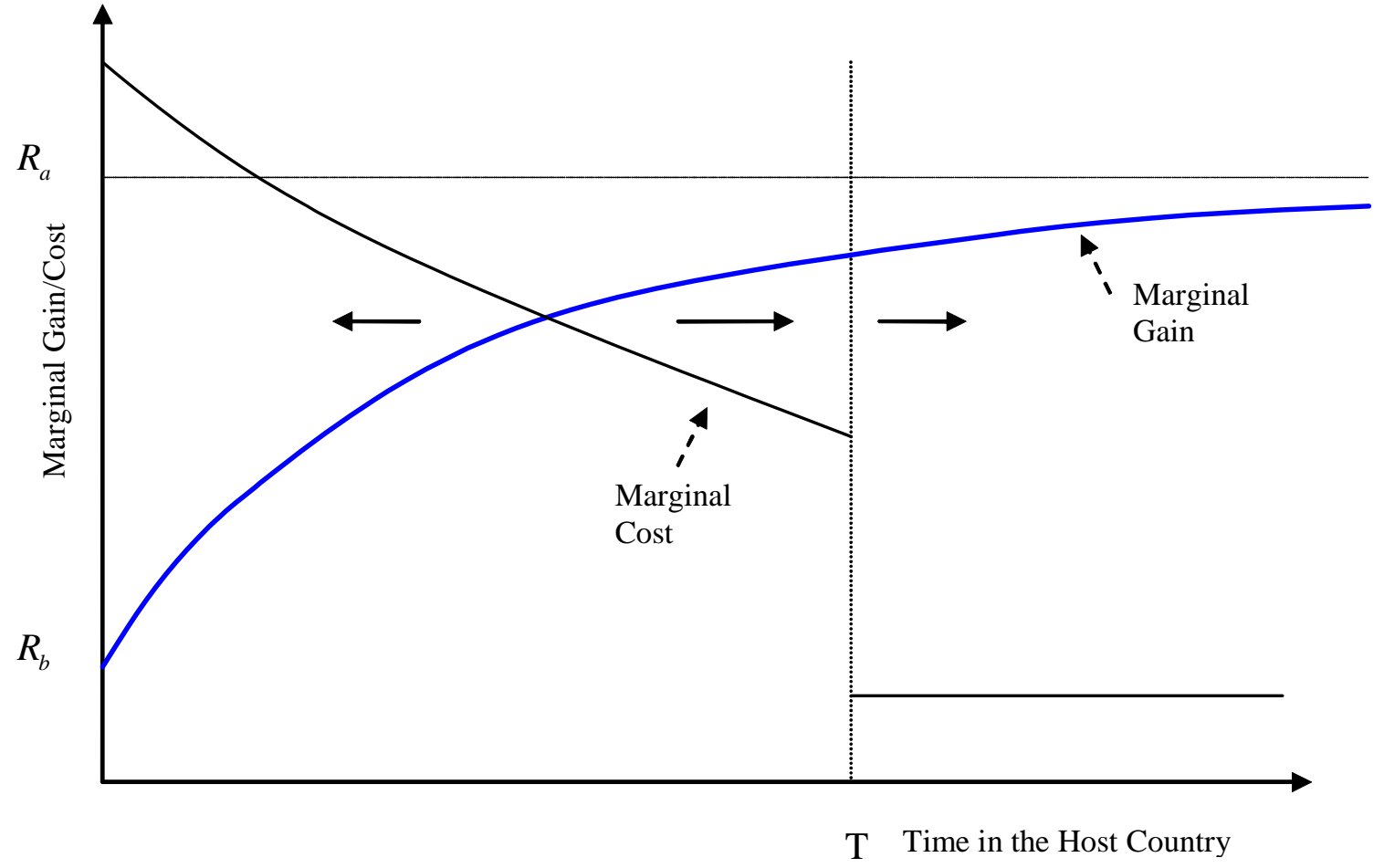

Figure 1: Determination of time in the host country, partial transferability 


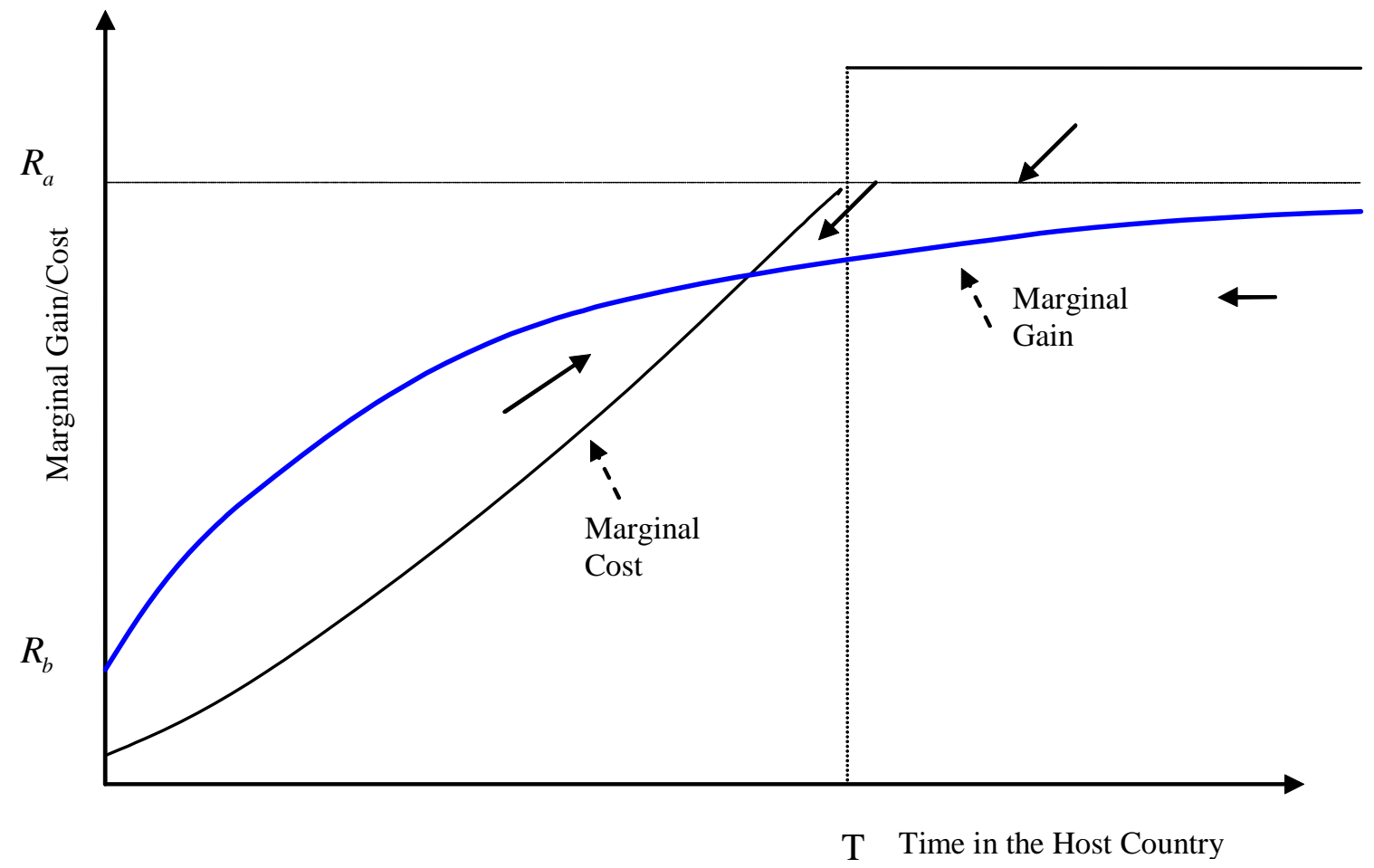

Figure 2: Determination of time in the host country, strong transferability 


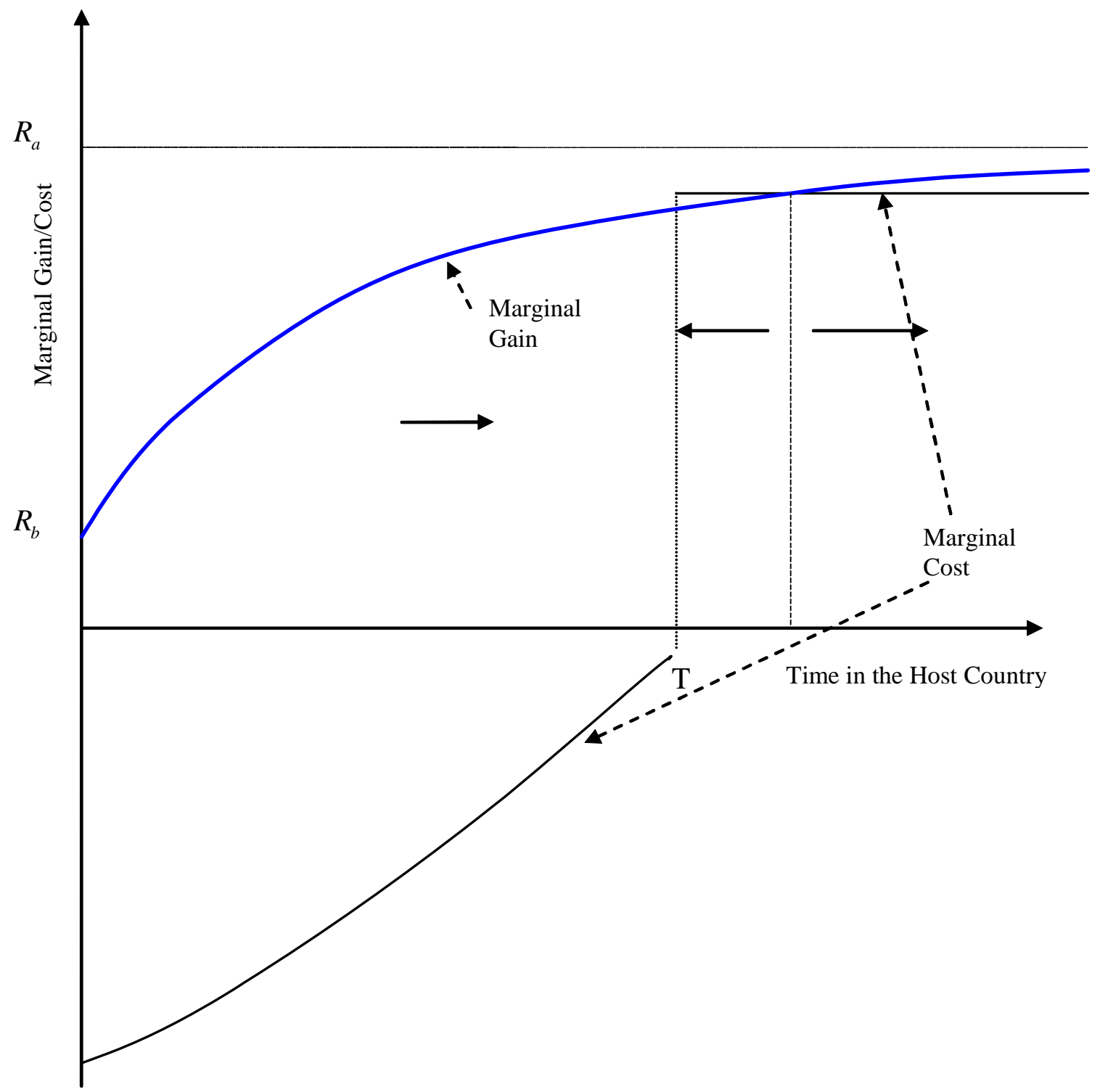

Figure 3: Determination of time in the host country, super transferability 


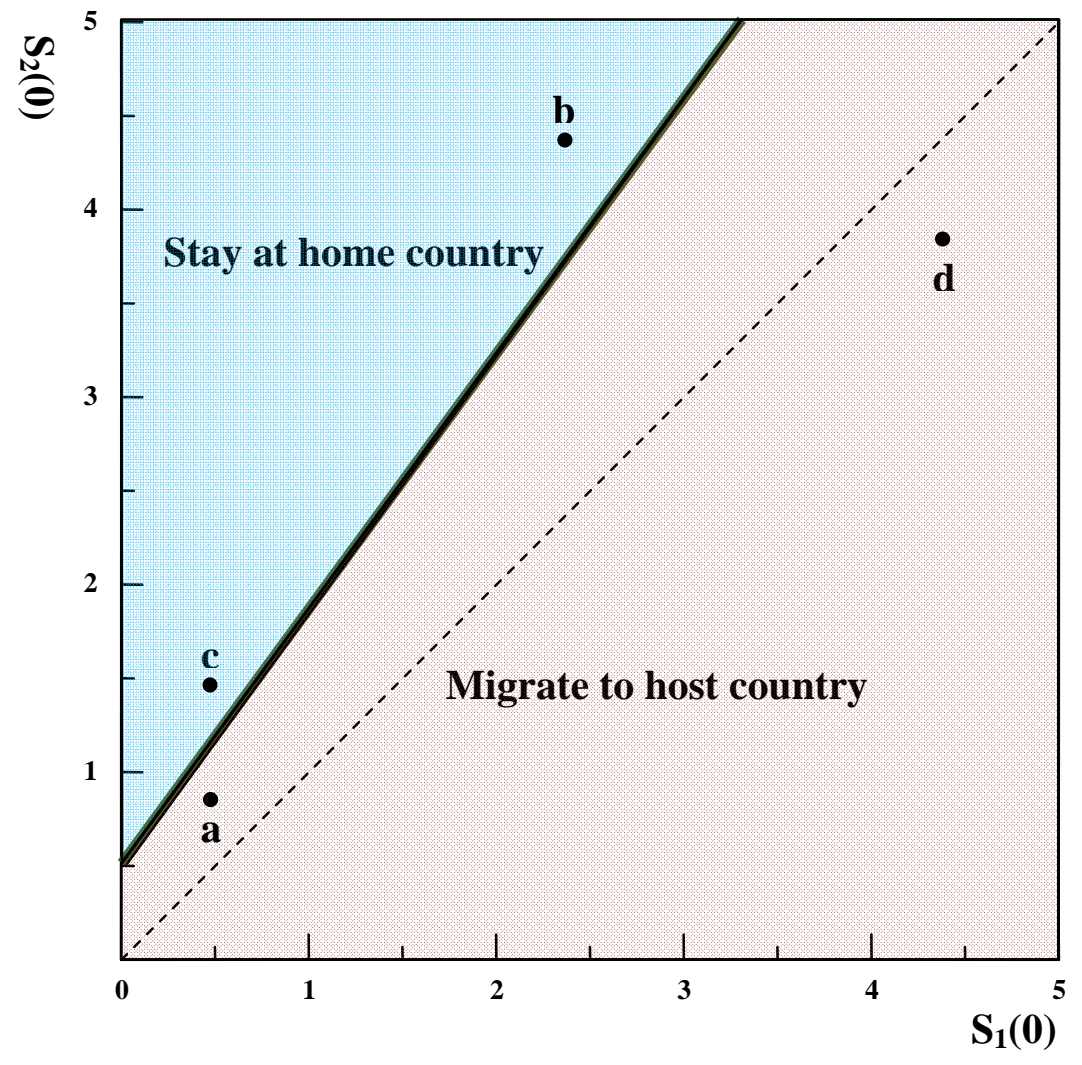

Figure 4: Determination of who emigrates, partial transferability 


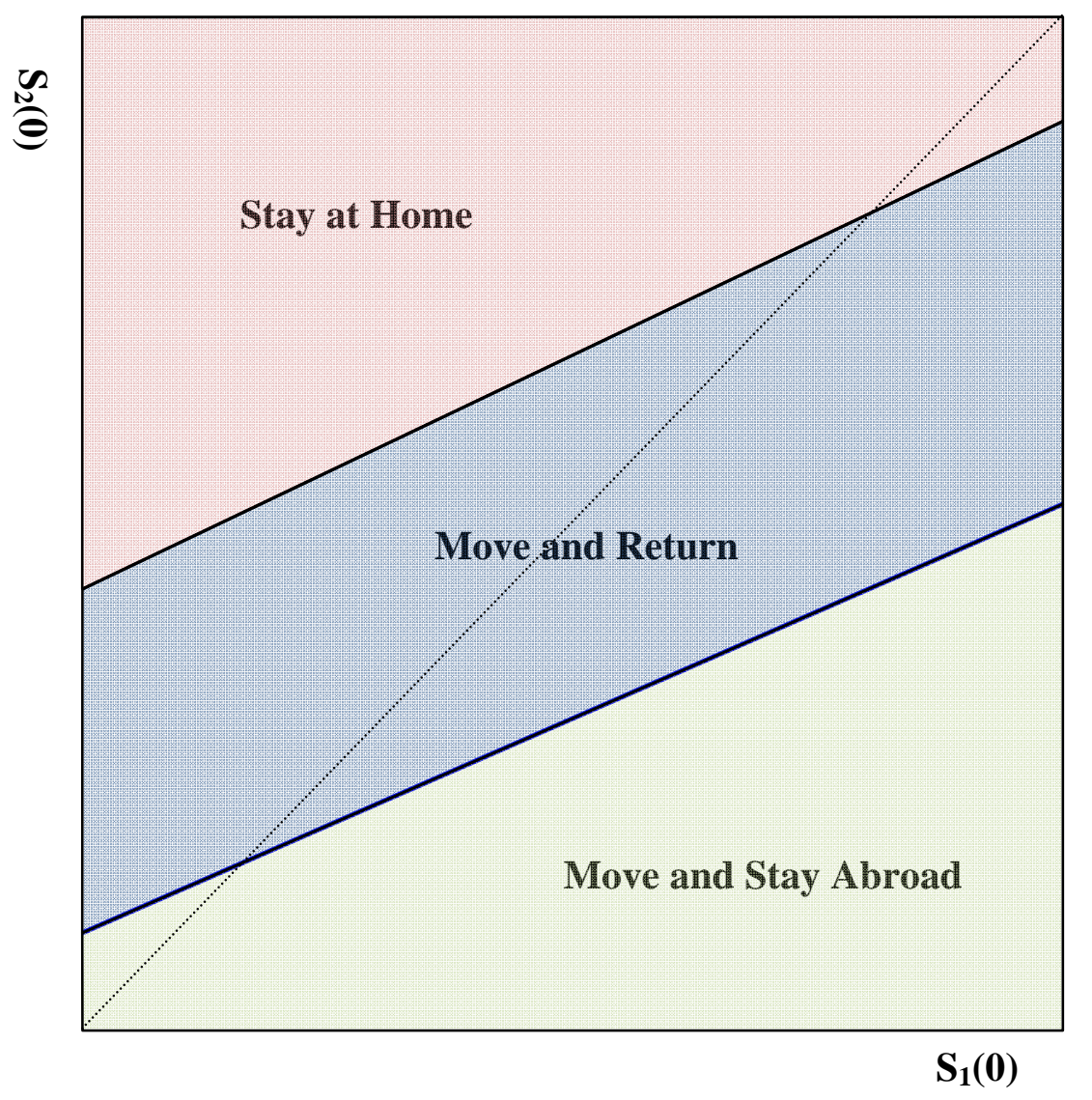

Figure 5: Emigration and return migration, strong transferability 


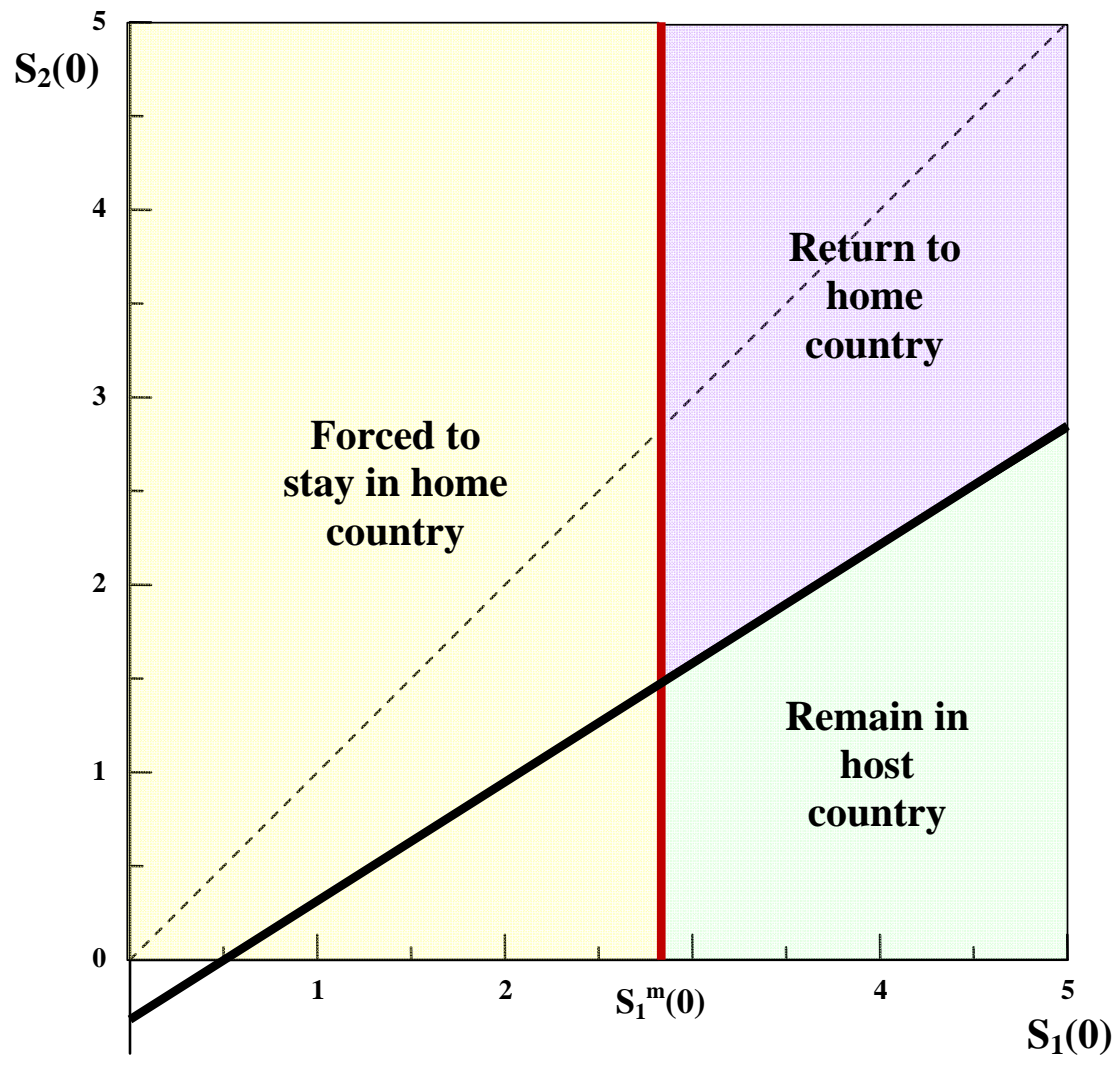

Figure 6: Emigration and return migration, super transferability 